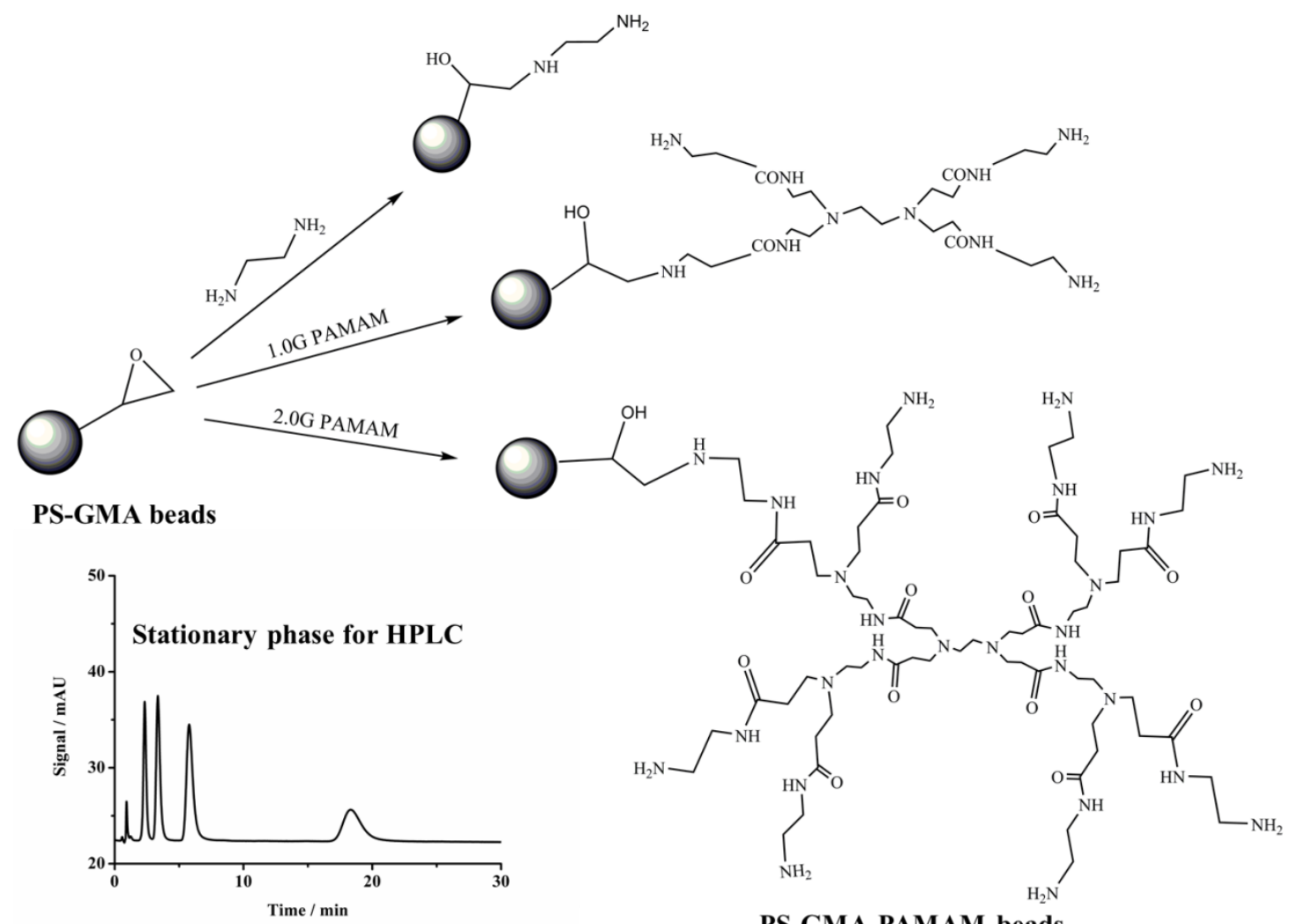

PS-GMA-PAMAM beads 


\title{
Poly (styrene-divinyl benzene-glycidylmethacrylate) stationary phase grafted with poly amidoamine (PAMAM) dendrimers for rapid determination of phenylene diamine isomers in HPLC
}

Dandan Guo ${ }^{\mathrm{a}}$, Chaoyan Lou ${ }^{\mathrm{a}}$, Nani Wang ${ }^{\mathrm{a}, \mathrm{d}}$, Meilan Chen ${ }^{\mathrm{c}}$, Peimin Zhang ${ }^{\mathrm{a}}$, Shuchao

$$
\mathrm{Wu}^{\mathrm{b} *}, \text { Yan } \mathrm{Zhu}^{\mathrm{a}, *}
$$

\begin{abstract}
A novel high performance liquid stationary phase was prepared by grafting poly amidoamine (PAMAM) dendrimers to poly (styrene-divinyl benzene-glycidylmethacrylate) matrix in this work. Different generations of PAMAM dendrimers grafted to polymer matrices containing different glycidylmethacrylate amounts by reacting with epoxy groups in glycidylmethacrylate molecules. The synthesized PAMAM dendrimers and stationary phase were characterized by fourier transform infrared spectroscopy, scanning electron microscope, $\mathrm{N}_{2}$ adsorption/desorption, elemental analysis and thermo gravimetric analyzer. The proposed stationary phase was suitable for rapid separation of phenylene diamine isomers and aminobenzene. The separation mechanism of benzene rings attraction and amino repulsion was verified by retention behaviors of methylamine, phenylamine, phenylene diamine, naphthylamine and toluene. The reliability of the stationary phase was demonstrated by separation and determination of phenylene diamine isomers including $m$-phenylene diamine, $o$-phenylene diamine and $p$-phenylene diamine in hair dye precursors within $10 \mathrm{~min}$. Satisfactory resolution and short analysis time make the columns promising for determination of aniline compounds in various fields.
\end{abstract}




\section{Introduction:}

Nowadays, phenylene diamine is widely used as an important chemical constituent along with other chemical compounds in various kinds of dyes, such as hair dyes, henna and azo dyes[1-3]. These toxic compositions are always responsible for many serious diseases like allergic dermatitis and cancers [4-6]. The abuse of these dyes has increased the health risk. Thus, a large amount of analytical methods have been developed for the separation and detection of this toxic substance, mainly including gas chromatography(GC), mass spectrometer(MS) [7, 8], gas chromatography-mass spectrometer (GC/MS) $[3,9,10]$, capillary electrophoresis (CE) $[11,12]$ and high performance liquid chromatography (HPLC) [2]. All of the proposed methods have separated phenylene diamine with other compounds successfully. However, there are three phenylene diamine isomers with different structures and toxicities. Dyes containing $m$-phenylene diamine (MPD) may have greater toxicity than these of $o$-phenylene diamine (OPD) and $p$-phenylene diamine (PPD). Rapid separation of phenylene diamine isomers is of great significance.

HPLC is one of the most useful methods for analysis of organic samples in various fields, such as environment, food, medicine and chemical engineering [13-16]. As the core component of HPLC system, columns packed with different particles have become a research focus [17-19]. Since the earliest day of HPLC column technology, silica is recognized as the most popular chromatographic support [20-22]. Stationary phase manufactured from silica matrix always has excellent mechanical properties and is easy for further derivatization. However, silica columns always have short service life in base mobile phase and high temperature, which limits the serviceable range of the columns [23, 24]. To improve chemical and thermal stabilities, organic polymer supports have been developed as HPLC stationary phase $[25,26]$. Organic polymers used for HPLC matrices are mainly synthesized from styrene, divinyl benzene, methacrylate, acrylates and acrylamide monomers [27-29]. 
Recently, glycidylmethacrylate (GMA) has attracted the attention of researchers as a new kind of monomers for polymer matrices. These polymers can be easily modified by various reagents and reactions, because of the large amount of epoxy groups on their surface [30, 31].

Dendrimers [32-34] are high branched tree like monodispersed macromolecules with a regular three-dimension structure. In general, dendrimers are composed of an initial core, a number of repeated units and a high density of surface groups. They have been extensively applied in various fields due to these special structures. For instance, as a result of their unique initial core structure, dendrimers are widely used in encapsulation and carriers in new catalysts [35]. They are perfect research subject for host-guest chemistry because of their repetitive hyperbranched structure and lots of space between branches [36]. The rich surface groups enable them good functional materials in synthesis. In addition, other merits such as excellent optical and electrical performance, good dispersion, low toxicity and biological compatibility make them more and more popular in electrochemistry, materials chemistry, nanotechnology, detection, and biological medicine areas [37, 38]. Nowadays, most research in dendrimers has focused on a special dendritic macromolecule named poly (amidoamine) (PAMAM) [39, 40]. PAMAM is one of the most common dendrimers because of its simple structure and easy synthesis. Synthesis procedure of PAMAM involves two steps: Michael addition and amidation reaction. Each step will produce a half generation $(G)$. Terminal group of half generation and whole generation of PAMAM are ester base and amino, respectively. These groups may play an important role in liquid chromatography separations. Thus, PAMAM may have extensive application prospects in modification of liquid chromatographic stationary phase.

In this study, a new kind of HPLC column modified by PAMAM was proposed for rapid separation of phenylene diamine isomers. The column was based on polystyrene-divinylbenzene-glycidylmethacrylate (PS-DVB-GMA) stationary phase. PAMAM was grafted to the stationary phase by direct reaction with epoxy group on surface of the matrix. Reliability of the column was demonstrated by separating OPD, PPD and MPD in hair dyes. The application of PAMAM dendrimers in HPLC 
polymer stationary phase was explored for the first time.

\section{Material and methods}

\subsection{Apparatus and instruments}

All chromatographic investigations were carried out on the Thermo Fisher Scientific Ultimate 3000 HPLC system, which was equipped with a LPG-3400SD pump, a TCC-100 thermostatted column compartment, a six-port valve fitted with a $20 \mu \mathrm{L}$ sample loop and a VWD-3400 variable-wavelength UV detector. The eluent flow rate was $1.2 \mathrm{~mL} \mathrm{~min}^{-1}$. The system temperature of all chromatographic tests was set at $30{ }^{\circ} \mathrm{C}$. Data were collected by Chromeleon 6.80 chromatography data management software (Thermo Fisher Scientific).

The scanning electron microscope (SEM) images were obtained using Hitachi SU-70 (Hitachi Japan). Fourier transform infrared (FTIR) spectroscopy was performed on a Bruker Vector 22 spectrometer (Bruker, Germany). Thermogravimetric analysis (TGA) was carried out on DSCQ1000 differential scanning calorimetry (TA, New Castle, Delaware, USA). The content of nitrogen in stationary phase was analyzed by utilizing an elemental analyzer (Flash EA1112, Thermofinnigan). The surface characteristics were investigated on a surface area and porosity analyzer ASAP 2020 HD88 (Micromeritics, Atlanta, Georgia, USA). The homemade columns were packed by the QP 6000 packing pump (Chuang Xin Tong Heng Science and Technology Co., Ltd., Beijing, China). All of the organic compounds were emulsified by an SB-5200DT ultrasonic equipment (Scientz, China) Water for all eluents and standard solutions was purified by a water purification system (Thermo Fisher Scientific) to a specific resistivity of $18.2 \mathrm{M} \Omega \mathrm{cm}$.

\subsection{Reagents}

Styrene (St), Azobisisobutyronitrile (AIBN), Dibutyl phthalate (DBP), sodium dodecylsulfonate (SDS), polyvinyl alcohol (PVA) and benzyl peroxide (BPO) were purchased from Huipu Chemical Reagent Co. Ltd. (Hangzhou, China). Ethylenediamine, methyl acrylate and 1, 4-butanediol diglycidyl ether (BDDE, 60\% in $\mathrm{H}_{2} \mathrm{O}$, v/v) were obtained from Aladdin Chemical Co. Ltd. (Shanghai, China). 
Styrene, DVB (55\%, Zhengguang Chemical Plant, Hangzhou, China) and GMA (97\%, Tokyo Kasei Kogyo Co., Ltd., Tokyo, Japan) were used after washing with 10\% (w/v) sodium hydroxide aqueous solution. AIBN and BPO were recrystallized before use. All of the standard solutions were prepared by dissolving appropriate amount of reagents in methanol (chromatographically pure). Hair dye samples were purchased from online shopping market. All reagents employed for the synthesis were of analytical grade.

\subsection{Preparation of chromatographic stationary phase}

\subsubsection{The production of PAMAM}

Different generations of PAMAM were synthesized according to the method described by Tomalia et al[32]. Ethylenediamine was used as a nitrogen core in synthetic procedure. As shown in Fig. 1, it involved 2 repeated steps: Michael addition and amidation reaction. Each step reacted for $24 \mathrm{~h}$ at $30{ }^{\circ} \mathrm{C}$. Production from each step was purified by rotary evaporation device.

\subsubsection{Preparation of PS-GMA beads}

Polymer seeds were firstly prepared by dispersion polymerization method. The typical procedure was as follows[41]: The reaction was conducted in a $250 \mathrm{~mL}$ four-necked round-bottomed flask. $3 \mathrm{~g}$ PVP and $100 \mathrm{~mL}$ mixture of ethanol and water (95:5, V/V) were added to the flask with $70{ }^{\circ} \mathrm{C}$ temperature-controlled water bath. After then, mixture of $18 \mathrm{~g}$ styrene and $0.8 \mathrm{~g}$ AIBN were added into the flask dropwise in 30 min. The seeds were washed with excess water and stored in 1\% SDS after reaction for $24 \mathrm{~h}$. Secondly, PS-GMA beads were synthesized by swelling and polymerization procedure. Polymer seeds were dispersed in $15 \mathrm{~mL}$ SDS aqueous $(0.2 \%, \mathrm{w} / \mathrm{v})$ and placed in a $500 \mathrm{~mL}$ three neck flask along with $30 \mathrm{~mL}$ SDS aqueous solution $(0.2 \%, \mathrm{w} / \mathrm{v})$ containing $4 \mathrm{~g}$ DBO. After stirring overnight, another mixture which was consisted of $30 \mathrm{~g}$ organic compounds dispersed in $250 \mathrm{~mL}$ PVA aqueous solution $(1.0 \%, \mathrm{w} / \mathrm{v})$ was added and swelled. The above organic compounds consisted of ST, DVB, GMA, toluene, BPO and SDS. The amount of toluene was equal to the sum of ST and DVB. The content of BPO and SDS were $0.6 \%$ and $2.5 \%(\mathrm{w} / \mathrm{w})$ of organic compounds. Different amount of GMA (3\%,6\% and 12\%, w/w) were added 
in different stationary phase. After $24 \mathrm{~h}$, the mixture were heated by water bath at 70 ${ }^{\circ} \mathrm{C}$ under nitrogen atmosphere and lasted for $24 \mathrm{~h}$. Subsequently, the resulting beads were washed successively with hot water and alcohol. Then, the beads were purified by soxhlet extraction with toluene for $48 \mathrm{~h}$. After washing by water and alcohol, the PS-GMA beads were dried under vacuum at $60^{\circ} \mathrm{C}$ for $24 \mathrm{~h}$.

\subsubsection{Preparation of PS-GMA-PAMAM stationary phase}

PS-GMA-PAMAM stationary phase was obtained by grafting PAMAM to the surface of PS-GMA beads. Specific as follows: $3.0 \mathrm{~g}$ PS-GMA beads were dispersed in $30 \mathrm{~mL}$ alcohol by ultrasonication for $10 \mathrm{~min}$. Then, the excessive ethylenediamine and PAMAM with different generations $(1.0 \mathrm{G}$ and $2.0 \mathrm{G})$ were added to the mixture separately and stirred at $70{ }^{\circ} \mathrm{C}$ for $1 \mathrm{~h}$. After being washed by water and methanol, the PS-GMA-PAMAM HPLC stationary phases were obtained (Fig. 2).

\subsection{Column packing procedure}

The columns were packed by a slurry method. 3.0 g PS-GMA-PAMAM stationary phases described above were dispersed in $50 \mathrm{~mL}$ deionized water to form slurry by ultra-sonication. The slurry consisting of modified matrix was packed into a column (stainless steel, $150 \mathrm{~mm} \times 4.6 \mathrm{~mm}$ i.d.) at the pressure of $200 \mathrm{bar}$. The volume of packing solvent passing through the column should be more than $350 \mathrm{~mL}$. The columns were flushed by methanol overnight before being connected to HPLC instrument.

\subsection{Sample preparation}

An accurate amount of hair dye precursors were dissolved in $5 \mathrm{~mL}$ methanol and sonicated for $5 \mathrm{~min}$. The solution was injected into HPLC system directly after being filtered through a $0.45 \mu \mathrm{m}$ membrane filter.

\section{Result and Discussion}

\subsection{FTIR spectra of PAMAM dendrimers}

The structure of the synthesized 0.5G PAMAM and 1.0G PAMAM dendrimers was confirmed by FTIR. As shown in Fig. 3, Absorption peaks at $2954 \mathrm{~cm}^{-1}$ and 2829 $\mathrm{cm}^{-1}$ were corresponding to $-\mathrm{CH}_{3}$ and $-\mathrm{CH}_{2}$ - groups in $0.5 \mathrm{G}$ PAMAM, respectively. 
The absorption bands at $1747 \mathrm{~cm}^{-1}$ and $1336-1042 \mathrm{~cm}^{-1}$ could be attributed to the stretching vibrations of $\mathrm{C}=\mathrm{O}$ and $-\mathrm{C}-\mathrm{O}-\mathrm{C}$ groups in $0.5 \mathrm{G}$ PAMAM. The absorption peak at $1462 \mathrm{~cm}^{-1}$ in $0.5 \mathrm{G}$ PAMAM was related to the $-\mathrm{CH}_{2^{-}}$bending vibration. Double absorption peaks in $3309 \mathrm{~cm}^{-1}$ and $3085 \mathrm{~cm}^{-1}$ were attributed to stretching vibration of $-\mathrm{NH}_{2}$ groups in 1.0G PAMAM. The significant peaks at $1642 \mathrm{~cm}^{-1}$ and $1573 \mathrm{~cm}^{-1}$ in $1.0 \mathrm{G}$ PAMAM were corresponding to $-\mathrm{CONH}-$ groups. The C-N stretching vibration in 1.0G PAMAM dendrimers can be observed at $1322 \mathrm{~cm}^{-1}$ and $1469 \mathrm{~cm}^{-1}$. No double absorption peaks of $-\mathrm{NH}_{2}$ was found in $0.5 \mathrm{G}$ PAMAM. And a wide band of -C-O-C groups between $1336 \mathrm{~cm}^{-1}$ and $1042 \mathrm{~cm}^{-1}$ was not observed in 1.0G PAMAM dendrimers, which is exactly consistent to PAMAM structures in Fig. $1[42]$.

3.2 Characterization of stationary phase

3.2.1 Surface feature and diameter of the particles

Surface and morphology characterizations of the stationary phase were characterized with SEM (Fig.4) and BET. The PS-GMA beads are uniform and monodisperse porous microspheres with average diameter of $5 \mu \mathrm{m}$. Surface of the beads is smooth with no sags or crests. The pore on the surface of the beads can be seen clearly under the electron microscope. Pore size of the PS-GMA beads investigated by BET was $5.98 \mathrm{~nm}$. After grafting with PAMAM, the morphology and size of the beads are basically the same, while the pore size on the surface increased to $6.28 \mathrm{~nm}$. The chemical modification of PAMAM denderimers has no significant impact on the particle surface morphology.

\subsubsection{Element analysis}

Five different columns were synthesized in this work, as shown in Table 1. Ethylenediamine and different generations of PAMAM (1.0G, 2.0G) grafted to the surface of PS-GMA beads with different content of GMA $(3 \%, 6 \%, 12 \%$, w/w). Element analysis was performed to evaluate the content of nitrogen in grafting beads (shown in Table 2). Because PS-DVB beads have no nitrogen, nitrogen content in stationary phase is proportional to the ratio of grafted PAMAM dendrimers. Comparing 6G1P stationary phase with $3 \mathrm{G} 1 \mathrm{P}$ and $12 \mathrm{G} 1 \mathrm{P}$, the percentages of nitrogen 
increased with more GMA content in PS-GMA beads. Meanwhile, increased nitrogen contents in 6G0P, 6G1P and 6G2P modified beads suggested that the percentages of nitrogen increased with the increase of PAMAM generations. Therefore, more functional groups will be obtained by increasing GMA content and PAMAM generations.

\subsubsection{Thermal stability of the beads}

The thermodynamic stability of PS-GMA beads and PS-GMA-PAMAM stationary phase were studied by Thermo Gravimetric Analyzer (TGA). As shown in Fig. 5, there is almost no weight loss for both PS-GMA beads and PS-GMA-PAMAM beads under $300{ }^{\circ} \mathrm{C}$, which verified that the beads can keep good thermal stability after being grafted with PAMAM.

\subsection{Retention behavior of phenylene diamine isomers in synthetic HPLC columns}

There are three different phenylene diamine isomers with amino groups located in ortho-position, para-position and meta-position. A mixture containing $o$-phenylene diamine, $p$-phenylene diamine, $m$-phenylene diamine and phenylamine was used to evaluate the separation effect of the column after modified by PAMAM dendrimers. $20 \mathrm{mg} \mathrm{L}^{-1}$ standard solution was separated by PS-GMA beads and PS-GMA-PAMAM beads, respectively. A mixture of methanol/water (50/50, v/v) was utilized as mobile phase in isocratic mode with a flow rate at $1.2 \mathrm{~mL} \mathrm{~min}^{-1}$. The wavelength for detection was $280 \mathrm{~nm}$. As shown in Fig. 6, retentions of the analytes in PS-GMA column were between 6-18 min with two wide peaks. However, phenylene diamine isomers in 6G1P column were separated with satisfactory resolution (Table 3). Grafting with PAMAM has improved the performance of the PS-GMA beads.

PAMAM was synthesized with ethylenediamine as a core. Each repeat unit in PAMAM was called a generation $(\mathrm{G})$. Columns modified by different generations of PAMAM were investigated under the same chromatography condition by phenylene diamines isomers. Representative chromatograms were shown in Fig. 7. All of the columns can separate the isomers successfully. Phenylene diamines have less retention time in $6 \mathrm{G} 1 \mathrm{P}$ than $6 \mathrm{G} 0 \mathrm{P}$ and $6 \mathrm{G} 2 \mathrm{P}$ column. Besides, retention behaviors on stationary phase with different content of GMA were also evaluated under the same 
condition by isomers. The result was shown in Fig. 8, retention time in columns decreased with the increasing of GMA contents.

\subsection{Separation mechanism}

According to retention behaviors in different columns, separation mechanism of the stationary phase was explored. Generally, there are 3 kinds of groups in the PS-GMA-PAMAM columns, including benzene rings, carbonyl groups and amino groups. Theoretically, retention ability is influenced by attraction forces between benzene rings in stationary phase and phenylene diamines, and repulsive forces between amino groups in PAMAM and amino groups in analytes. Thus, more GMA content in beads should graft more PAMAM. Much PAMAM on the surface of beads would decrease attraction force between benzene rings. Besides, large amount of PAMAM terminal amino groups in stationary phase will increase amino repulsion. Consequently, retention time of phenylene diamines decreased with increasing GMA contents, which is consisted with the result in Fig. 8. Similarly, different generations of PAMAM grafted to PS-GMA beads will cover the benzene ring at different degrees. Attraction forces between benzene rings will be lower in beads grafted with high generation of PAMAM. In addition, high generation of PAMAM will have more amino groups and increase amino repulsion. As 6G0P and 6G1P curves shown in Fig. 7, with increasing generation of PAMAM grafted to the beads, retention time in stationary phase will be decreased. However, retention time of phenylene diamines in 6G2P is longer than 6G1P in Fig. 7, which is account for $\pi-\pi$ conjugate effect between benzene rings in phenylene diamines and carbonyl groups in PAMAM. With increase of PAMAM generations, carbonyl groups increase rapidly and $\pi-\pi$ conjugate will have a greater impact than amino repulsion.

Based on this assumption, methylamine, phenylamine, naphthylamine, phenylene diamines and toluene were separated by the 6G1P stationary phase to verify the mechanism above. The chromatograms are shown in Fig. 9. The mixture of methanol/water (70/30, v/v) was used as eluent under isocratic mode with flow rate at $1.2 \mathrm{~mL} \mathrm{~min}^{-1}$. Methylamine, phenylamine and naphthylamine were separated in Fig. 9a. The result was detected by a UV detector with the wavelength at $215 \mathrm{~nm}$. 
Mathylamine without benzene rings has almost no retention in column. Retention time of naphthylamine is longer than phenylamine because of more benzene rings. As shown in Fig. 9b, phenylene diamine, phenylamine and toluene were separated by the column and detected by a UV detector with the wavelength at $280 \mathrm{~nm}$. Phenylene diamine with two amino groups was eluted out firstly. Phenylamine with one amino group was eluted out subsequently. Toluene cannot be eluted out with $70 \%$ methanol eluent until 20 min because of no amino group in structure. Therefore, more benzene rings in structure will result in longer retention time, while more amino groups in molecular will result in less retention time. The results are consistent with the mechanism of benzene rings attraction and amino repulsion.

3.5 Determination of phenylene diamine isomers in hair dye precursors

Reliabilities of the synthetic HPLC columns were investigated by determination of phenylene diamine isomers in hair dye precursors. Series standard solutions with concentrations varying form $1 \mathrm{mg} \mathrm{L}^{-1}$ to $20 \mathrm{mg} \mathrm{L}^{-1}$ were detected under isocratic mode. The mobile phase was consisted of methanol/water $(50 / 50, \mathrm{v} / \mathrm{v})$ mixture and the flow rate was $1.2 \mathrm{~mL} \mathrm{~min}^{-1}$. A UV detector was used to detect the results with the wavelength at $280 \mathrm{~nm}$. Linearity, limits of detection and limits of quantification of phenylene diamine isomers are shown in Table 4. The result showed a good linearity with correlation coefficient more than 0.9989. The limit of detection (LOD) was determined based on the signal to noise $(\mathrm{S} / \mathrm{N})$ ratio of 3 and the limit of quantification (LOQ) was determined based on the signal to noise $(\mathrm{S} / \mathrm{N})$ ratio of 10 . The relative standard deviations (RSDs) for retention time, peak area and peak height were in the range of $0.4 \%-2.3 \%$. The chromatograms of hair dye precursors and standard solution were shown in Fig. 10. Phenylene diamine isomers in practical samples are separated successfully by the synthetic column. $5 \mathrm{mg} \mathrm{L}^{-1}$ standard solutions were added into the samples, the average recovery of MPD, PPD and OPD were $87 \%$ 104\%. Only $0.0152 \mathrm{mg} / \mathrm{g}$ MPD was detected in sample 1 . The detected concentrations of MPD, PPD and OPD in sample 2 were $0.343 \mathrm{mg} / \mathrm{g}, 0.0100 \mathrm{mg} / \mathrm{g}$ and $0.0205 \mathrm{mg} / \mathrm{g}$, respectively. 


\section{Conclusion}

A novel PAMAM grafting HPLC column based on PS-GMA stationary phase was artificially synthesized for the separation of phenylene diamine isomers. Different generations of PAMAM and matrix containing various GMA amounts were utilized in synthesis procedure. The structure, chemical composition and thermodynamic stability of PAMAM dendrimers and the columns were verified by FTIR, SEM, BET, element analysis and TGA. All of the homemade columns have rapidly separated the phenylene diamine isomers with good symmetry and satisfactory resolution. Retention ability of the columns was closely related to GMA contents and PAMAM generations. Mechanism for phenylene diamine isomers separations in columns were explored and explained. According to the proposed mechanism, the homemade column is expected to have a broad prospect in separation of aniline category matters.

\section{Acknowledgements}

This work was financially supported by National Science Foundation of China (Nos. 21405141), Key Laboratory of Health Risk Appraisal for Trace Toxic Chemicals of Zhejiang Province (2014006, 2014007), National Important Project on Science Instrument (Nos. 2012YQ09022903), Zhejiang Provincial Natural Science Foundation of China(Nos. LZ16B050001 LY15B050001, S16H180002).

\section{Reference}

[1] M. Gube, K. Heinrich, P. Dewes, P. Brand, T. Kraus, T. Schettgen, Internal exposure of hairdressers to permanent hair dyes: a biomonitoring study using urinary aromatic diamines as biomarkers of exposure, Int. Arch. Occup. Environ. Health 84(3) (2011) 287-292.

[2] M. Narita, K. Murakami, J.M. Kauffmann, Determination of dye precursors in hair coloring products by liquid chromatography with electrochemical detection, Analytica Chimica Acta 588(2) (2007) 316-320.

[3] M. Akyuz, S. Ata, Determination of aromatic amines in hair dye and henna samples by ion-pair extraction and gas chromatography-mass spectrometry, J. Pharm. Biomed. Anal. 47(1) (2008) 68-80.

[4] G.J. Nohynek, R. Fautz, F. Benech-Kieffer, H. Toutain, Toxicity and human health risk of hair dyes, Food Chem. Toxicol. 42(4) (2004) 517-543. 

Biotransformation of para-aminophenol and para-phenylenediamine in reconstructed human epidermis and human hepatocytes, Toxicol. Lett. 158(3) (2005) 196-212.

[6] M.K. Bharali, K. Dutta, Testicular toxicity of para-phenylenediamine after subchronic topical application in rat, Int. J. Environ. Health Res. 22(3) (2012) 270-278.

[7] W.Y. Chen, T.A.N. Nkosi, S. Combrinck, A.M. Viljoen, C. Cartwright-Jones, Rapid analysis of the skin irritant p-phenylenediamine (PPD) in henna products using atmospheric solids analysis probe mass spectrometry, J. Pharm. Biomed. Anal. 128 (2016) 119-125.

[8] K.M. Mohamed, D. Cromarty, V. Steenkamp, Development and validation of an LC-MS/MS method for determination of p-phenylenediamine and its metabolites in blood samples, J. Chromatogr. B 997 (2015) 1-6.

[9] T. Schettgen, K. Heinrich, T. Kraus, M. Gube, Determination of 2,5-toluylenediamine (2,5-TDA) and aromatic amines in urine after personal application of hair dyes: kinetics and doses, Arch. Toxicol. 85(2) (2011) 127-133.

[10] M.L. Di Gioia, A. Leggio, A. Le Pera, A. Liguori, A. Napoli, F. Perri, C. Siciliano, Determination by gas chromatography/mass spectrometry of p-phenylenediamine in hair dyes after conversion to an imine derivative, Journal of Chromatography A 1066(1-2) (2005) 143-148.

[11] S.Q. Dong, L.Z. Chi, S. Zhang, P.G. He, Q.J. Wang, Y.Z. Fang, Simultaneous determination of phenylenediamine isomers and dihydroxybenzene isomers in hair dyes by capillary zone electrophoresis coupled with amperometric detection, Anal. Bioanal. Chem. 391(2) (2008) 653-659.

[12] X.J. Huang, T.Y. You, T. Li, X.R. Yang, E.K. Wang, End-column electrochemical detection for aromatic amines with high performance capillary electrophoresis, Electroanalysis 11(13) (1999) 969-972.

[13] Z.Q. Luo, Z.Q. Deng, Y. Liu, G.P. Wang, W.N. Yang, C.B. Hou, M.M. Tang, R.R. Yang, H.M. Zhou, Development and validation of a novel stability-indicating HPLC method for the quantitative determination of eleven related substances in ezetimibe drug substance and drug product, Talanta 139 (2015) 67-74.

[14] J. Stachniuk, P. Kubalczyk, P. Furmaniak, R. Glowacki, A versatile method for analysis of saliva, plasma and urine for total thiols using HPLC with UV detection, Talanta 155 (2016) 70-77.

[15] T.C. de Figueiredo, D.C.S. de Assis, L.D.M. Menezes, G.R. da Silva, I.P. Lanza, L.G.D. Heneine, S.D. Cancado, HPLC-UV method validation for the identification and quantification of bioactive amines in commercial eggs, Talanta 142 (2015) 240-245.

[16] L. Rivoira, R.M. De Carlo, S. Cavalli, M.C. Bruzzoniti, Simple SPE-HPLC determination of some common drugs and herbicides of environmental concern by pulsed amperometry, Talanta 131 (2015) 205-212. 
[17] Q. Wang, G.A. Baker, S.N. Baker, L.A. Colon, Surface confined ionic liquid as a stationary phase for HPLC, Analyst 131(9) (2006) 1000-1005.

[18] L. Maldaner, I. Jardim, A new thermally immobilized fluorinated stationary phase for RP-HPLC, J. Sep. Sci. 33(2) (2010) 174-181.

[19] A.R.B. de Quiros, M.A. Lage-Yusty, J. Lopez-Hernandez, HPLC analysis of organic acids using a novel stationary phase, Talanta 78(2) (2009) 643-646.

[20] R.X. Ran, L.J. You, B. Di, W.Q. Hao, M.X. Su, F. Yan, L.L. Huang, A novel chiral mesoporous binaphthyl-silicas: Preparation, characterization, and application in HPLC, J. Sep. Sci. 35(15) (2012) 1854-1862. [21] E. Menna, F. Della Negra, M. Prato, N. Tagmatarchis, A. Ciogli, F. Gasparrini, D. Misiti, C. Villani, Carbon nanotubes on HPLC silica microspheres, Carbon 44(8) (2006) 1609-1613.

[22] Q.S. Qu, Y. Min, L.H. Zhang, Q. Xu, Y.D. Yin, Silica Microspheres with Fibrous Shells: Synthesis and Application in HPLC, Analytical Chemistry 87(19) (2015) 9631-9638.

[23] A.M. Faria, E. Tonhi, K.E. Collins, C.H. Collins, Stability studies of stationary phases from ploy(methyltetradecylsiloxane) sorbed and immobilized onto metalized and unmodified silicas, J. Sep. Sci. 30(12) (2007) 1844-1851.

[24] E.M. Borges, M.R. Euerby, An appraisal of the chemical and thermal stability of silica based reversed-phase liquid chromatographic stationary phases employed within the pharmaceutical environment, J. Pharm. Biomed. Anal. 77 (2013) 100-115.

[25] T. Payagala, E. Wanigasekara, D.W. Armstrong, Synthesis and chromatographic evaluation of new polymeric chiral stationary phases based on three (1S,2S)-(-)-1,2-diphenylethylenediamine derivatives in HPLC and SFC, Anal. Bioanal. Chem. 399(7) (2011) 2445-2461.

[26] R. Li, J. Zhong, M.B. Hao, L.G. Bai, G.L. Yang, Preparation of a porous functional polymer and its application in the separation of small molecules in conjunction with HPLC, Anal. Methods 6(2) (2014) 589-595.

[27] K. Lungfiel, A. Seubert, Varying the porous structure of polystyrene/divinylbenzene beads prepared by Ugelstads activated swelling technique and examining its reversed phase HPLC properties, Journal of Chromatography A 1358 (2014) 117-127.

[28] F. Yang, Q. Bai, K.L. Zhao, D. Gao, L. Tian, Preparation of a novel weak cation exchange/hydrophobic interaction chromatography dual-function polymer-based stationary phase for protein separation using "thiol-ene click chemistry", Anal. Bioanal. Chem. 407(6) (2015) 1721-1734.

[29] A. Rahayu, L.W. Lim, T. Takeuchi, Polymer monolithic methacrylate base modified with 
tosylated-polyethylene glycol monomethyl ether as a stationary phase for capillary liquid chromatography, Talanta 134 (2015) 232-238.

[30] A. Srisopa, Preparation of monodisperse porous poly (glycidylmethacrylate-co-ethylenedimethacrylate) microspheres and their application as stationary phase for superheated water HPLC, Talanta 147 (2016) 358-363.

[31] J.W. Liu, Y. Wang, W.X. Li, P.M. Zhang, N.I. Wang, S.C. Wu, Y. Zhu, Octadecylamine-modified poly (glycidylmethacrylate-divinylbenzene) stationary phase for HPLC determination of N-nitrosamines, Talanta 160 (2016) 298-305.

[32] D.A. Tomalia, Starburst dendrimers-molecular-level control of size, shape, surface-chemistry, topology, and flexibility from atoms to macroscopic matter, Abstr. Pap. Am. Chem. Soc. 199 (1990) 315-ORGN.

[33] D.A. Tomalia, H. Baker, J. Dewald, M. Hall, G. Kallos, S. Martin, J. Roeck, J. Ryder, P. Smith, A new class of polymers-starburst-dendritic macromolecules, Polym. J. 17(1) (1985) 117-132.

[34] S.M. Grayson, J.M.J. Frechet, Convergent dendrons and dendrimers: from synthesis to applications, Chem. Rev. 101(12) (2001) 3819-3867.

[35] J. Zheng, S.Y. Lin, X.H. Zhu, B.W. Jiang, Z. Yang, Z.Y. Pan, Reductant-directed formation of PS-PAMAM-supported gold nanoparticles for use as highly active and recyclable catalysts for the aerobic oxidation of alcohols and the homocoupling of phenylboronic acids, Chem. Commun. 48(50) (2012) 6235-6237.

[36] K. Borowska, B. Laskowska, A. Magon, B. Mysliwiec, M. Pyda, S. Wolowiec, PAMAM dendrimers as solubilizers and hosts for 8-methoxypsoralene enabling transdermal diffusion of the guest, Int. J. Pharm. 398(1-2) (2010) 185-189.

[37] L. Uram, M. Szuster, A. Filipowicz, K. Gargasz, S. Wolowiec, E. Walajtys-Rode, Different patterns of nuclear and mitochondrial penetration by the G3 PAMAM dendrimer and its biotin-pyridoxal bioconjugate BC-PAMAM in normal and cancer cells in vitro, Int. J. Nanomed. 10 (2015) 5647-5661.

[38] G. Ying, G. Yujun, Q. Weidong, Polyamidoamine dendrimers as sweeping agent and stationary phase for rapid and sensitive open-tubular capillary electrophoretic determination of heavy metal ions, Talanta 121 (2014) 50-55. [39] H.Y. Deng, Y.Y. Xu, X.Z. Wei, B.K. Zhu, A novel nanofiltration membrane prepared with PAMAM and TMC (I), Chin. J. Polym. Sci. 26(6) (2008) 659-668.

[40] D.D. Guo, C.Y. Lou, P.M. Zhang, J.J. Zhang, N.N. Wang, S.C. Wu, Y. Zhu, Polystyrene-divinylbenzene-glycidyl methacrylate stationary phase grafted with poly (amidoamine) dendrimers for ion chromatography, Journal of Chromatography A 1456 (2016) 113-122.

[41] Y.Y. Zhong, W.F. Zhou, P.M. Zhang, Y. Zhu, Preparation, characterization, and analytical applications of a 
novel polymer stationary phase with embedded or grafted carbon fibers, Talanta 82(4) (2010) 1439-1447.

[42] J.C.Y. Chan, K. Burugapalli, H. Naik, J.L. Kelly, A. Pandit, Amine functionalization of cholecyst-derived extracellular matrix with generation 1 PAMAM dendrimer, Biomacromolecules 9(2) (2008) 528-536. 


\section{Tables}

Table 1

5 columns synthesized with different generations of PAMAM and contents of GMA

\begin{tabular}{cccc}
\hline PAMAM generations & $\begin{array}{c}\text { OG PAMAM } \\
\text { (ethylenediamine) }\end{array}$ & 1.0G PAMAM & $2.0 \mathrm{G}$ PAMAM \\
\hline $3 \%$ GMA & $*$ & $3 \mathrm{G} 1 \mathrm{P}$ & $*$ \\
$6 \% \mathrm{GMA}$ & $6 \mathrm{G} 0 \mathrm{P}$ & $6 \mathrm{G} 1 \mathrm{P}$ & $6 \mathrm{G} 2 \mathrm{P}$ \\
$12 \% \mathrm{GMA}$ & $*$ & $12 \mathrm{G} 1 \mathrm{P}$ & $*$ \\
\hline
\end{tabular}

Table 2

Element analysis of stationary phases

\begin{tabular}{lccc}
\hline \multicolumn{1}{c}{ Stationary phase } & Carbon $(\%)$ & Nitrogen $(\%)$ & Hydrogen $(\%)$ \\
\hline PS-6\% GMA & 87.29 & 0 & 8.15 \\
PS-3\% GMA-1.0G PAMAM & 84.52 & 0.13 & 7.637 \\
PS-6\% GMA-0G PAMAM & 81.47 & 0.34 & 7.409 \\
PS-6\% GMA-1.0G PAMAM & 86.00 & 0.39 & 7.969 \\
PS-6\% GMA-2.0G PAMAM & 85.12 & 0.44 & 7.806 \\
PS-12\% GMA-1.0G PAMAM & 81.94 & 0.76 & 7.981 \\
\hline
\end{tabular}

Table 3

The separation of phenylene diamine isomers with $6 \mathrm{G} 1 \mathrm{P}$ columns

\begin{tabular}{lccccc}
\hline & Resolutions & Asymmetry factor & \multicolumn{3}{c}{ RSD (n=6) \% } \\
\cline { 4 - 6 } & & & Peak area & Peak height & Retention time \\
\hline$p$-phenylene diamine & 2.17 & 1.06 & 2.53 & 2.62 & 0.00 \\
$m$-phenylene diamine & 3.08 & 1.25 & 2.13 & 2.84 & 0.25 \\
$o$-phenylene diamine & n.a & 1.31 & 0.52 & 2.18 & 1.69 \\
\hline
\end{tabular}

Table 4

Calibration parameters (five data points) for the three analytes in standard solutions.

\begin{tabular}{lcccl}
\hline & linear equation & $\begin{array}{c}\text { Correlation } \\
\text { coefficient }\left(\mathrm{R}^{2}\right)\end{array}$ & $\begin{array}{l}\mathrm{LOD}\left(\mu \mathrm{g} \mathrm{L}^{-1}\right) \\
(\mathrm{S} / \mathrm{N}=3)\end{array}$ & $\begin{array}{l}\mathrm{LOQ}\left(\mathrm{mg} \mathrm{L}^{-1}\right) \\
(\mathrm{S} / \mathrm{N}=10)\end{array}$ \\
\hline$p$-phenylene diamine & $\mathrm{y}=0.1967 \mathrm{x}-0.1086$ & 0.9989 & 57.9 & 0.193 \\
$m$-phenylene diamine & $\mathrm{y}=0.1391 \mathrm{x}+0.0206$ & 0.9999 & 53.1 & $0 . .177$ \\
$o$-phenylene diamine & $\mathrm{y}=0.1858 \mathrm{x}+0.1320$ & 0.9995 & 59.7 & 0.199 \\
\hline
\end{tabular}




\section{Captions}

Fig. 1 The synthesis procedure of different generations of PAMAM dendrimers

Fig. 2 Preparation of PS-GMA-PAMAM stationary phase by grafting with different PAMAM generations

Fig. 3 FTIR of 0.5G PAMAM and 1.0G PAMAM dendrimers

Fig. 4 SEM images of PS-GMA beads (a) $\times 2000$ times, (b) $\times 10000$ times, (c) $\times 40000$ times and PS-GMA-PAMAM stationary phase $(d) \times 2000$ times, $(e) \times 10000$ times, $(f)$ $\times 40000$ times

Fig. 5 Thermogravimetric analysis of PS-GMA beads (A) and PS-GMA-PAMAM (B) particles, conducted in nitrogen atmosphere: heating rate: $10{ }^{\circ} \mathrm{C} \mathrm{min}{ }^{-1}$

Fig. 6 Separation of phenylene diamine isomers and phenylamine with 6G1P column and PS-GMA beads. Column dimensions: $4.0 \mathrm{~mm}$ I.D. by $150 \mathrm{~mm}$; eluent: methanol/water $(50 / 50, \mathrm{v} / \mathrm{v})$; flow rate: $1.2 \mathrm{~mL} \mathrm{~min}^{-1}$; detection wavelength: $280 \mathrm{~nm}$; (1) PPD, (2) MPD, (3) OPD, (4) phenylamine.

Fig. 7 Separation of phenylene diamine isomers with columns modified by different generations of PAMAM. Column dimensions: $4.0 \mathrm{~mm}$ I.D. by $150 \mathrm{~mm}$; eluent: methanol/water (50/50, v/v); flow rate: $1.2 \mathrm{~mL} \mathrm{~min}^{-1}$; detection wavelength: $280 \mathrm{~nm}$; (1) PPD, (2) MPD, (3) OPD.

Fig. 8 Separation of phenylene diamine isomers with modified columns containing different GMA amounts. Column dimensions: $4.0 \mathrm{~mm}$ I.D. by $150 \mathrm{~mm}$; eluent: methanol/water $(50 / 50, \mathrm{v} / \mathrm{v})$; flow rate: $1.2 \mathrm{~mL} \mathrm{~min}^{-1}$; detection wavelength: $280 \mathrm{~nm}$; (1) PPD, (2) MPD, (3) OPD. 
Fig. 9 Separation of (a) methylamine, phenylamine, naphthylamine and (b) phenylamine, phenylene diamines, toluene in 6G1P column. Column dimensions: 4.0 mm I.D. by $150 \mathrm{~mm}$; eluent: methanol/water $(70 / 30, \mathrm{v} / \mathrm{v})$; flow rate: $1.2 \mathrm{~mL} \mathrm{~min}^{-1}$; detection wavelength: (a) $215 \mathrm{~nm}$, (b) $280 \mathrm{~nm}$.

Fig. 10 Detection of PPD, MPD and OPD in hair dye precursors with 3G1P column. Column dimensions: $4.0 \mathrm{~mm}$ I.D. by $150 \mathrm{~mm}$; eluent: methanol/water (50/50, v/v); inject volume: $20 \mu \mathrm{L}$; flow rate: $1.2 \mathrm{~mL} \mathrm{~min}^{-1}$; detection wavelength: $280 \mathrm{~nm}$. 
Fig 1

${ }_{10 \mathrm{~N}}^{\mathrm{Ni}_{2}}+$

6G.<smiles>COC(=O)CCN(CCC(=O)OC)CCN(CCC(=O)OC)CCC(=O)OC</smiles>
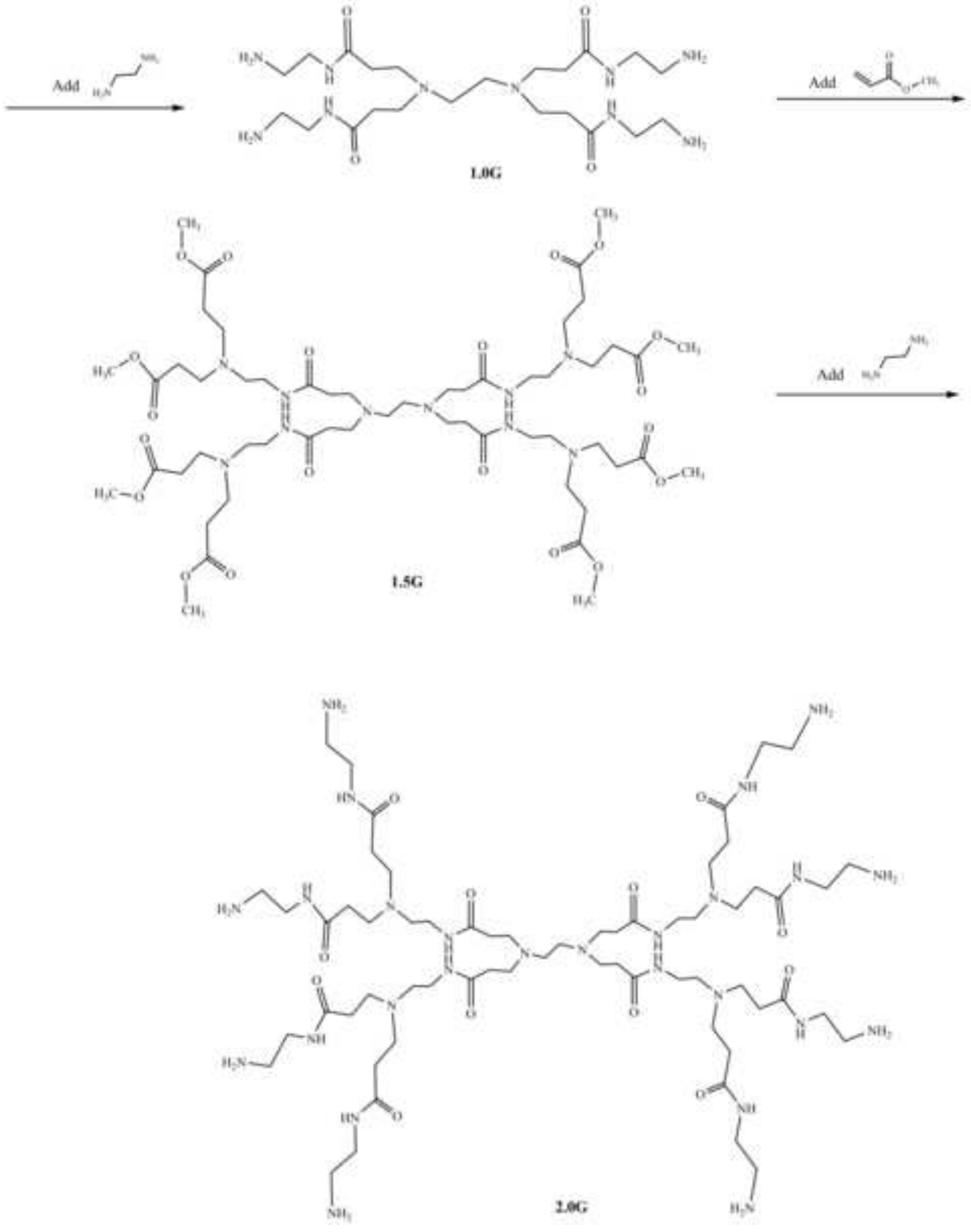

$$
\text { . }
$$




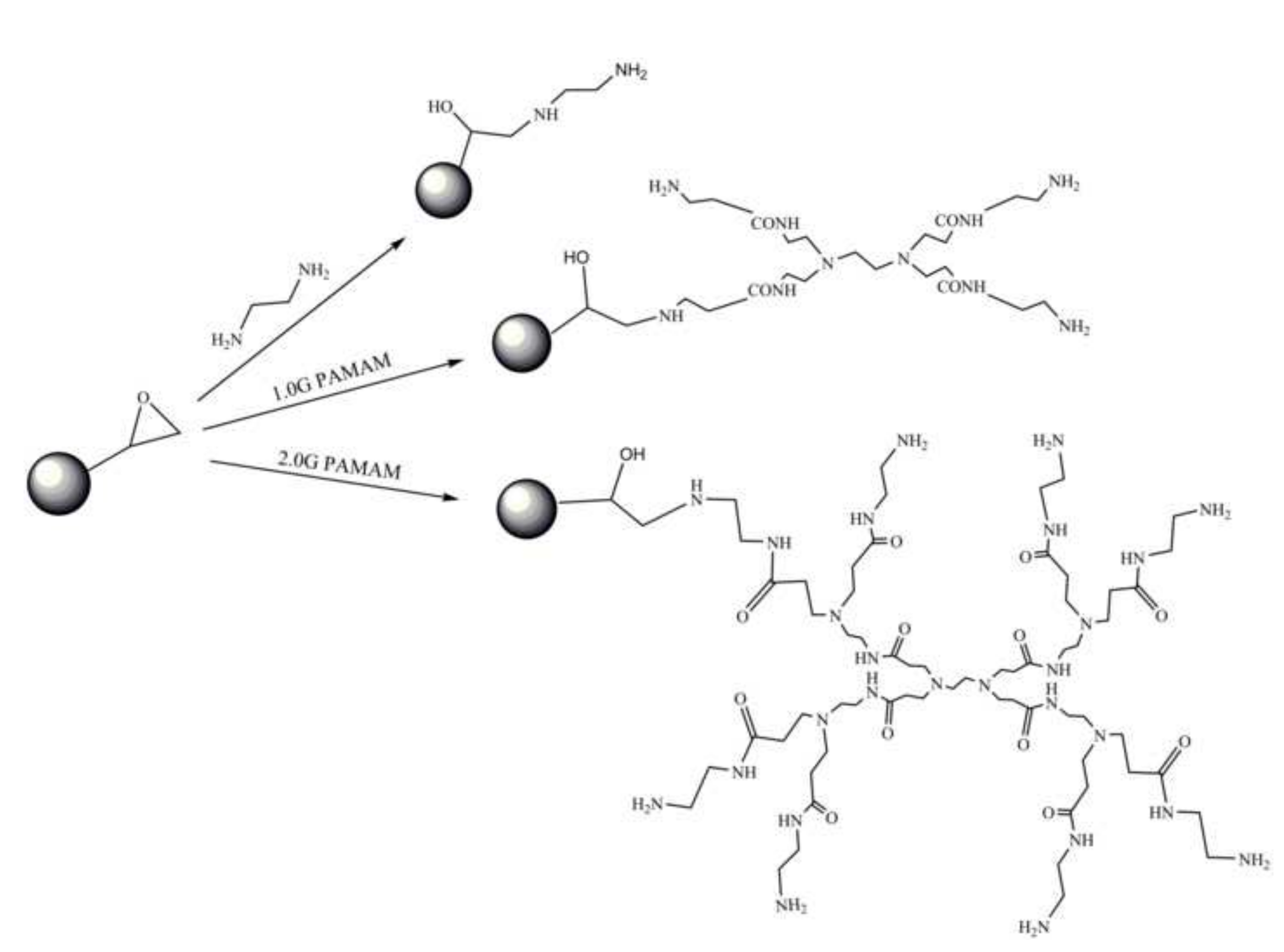




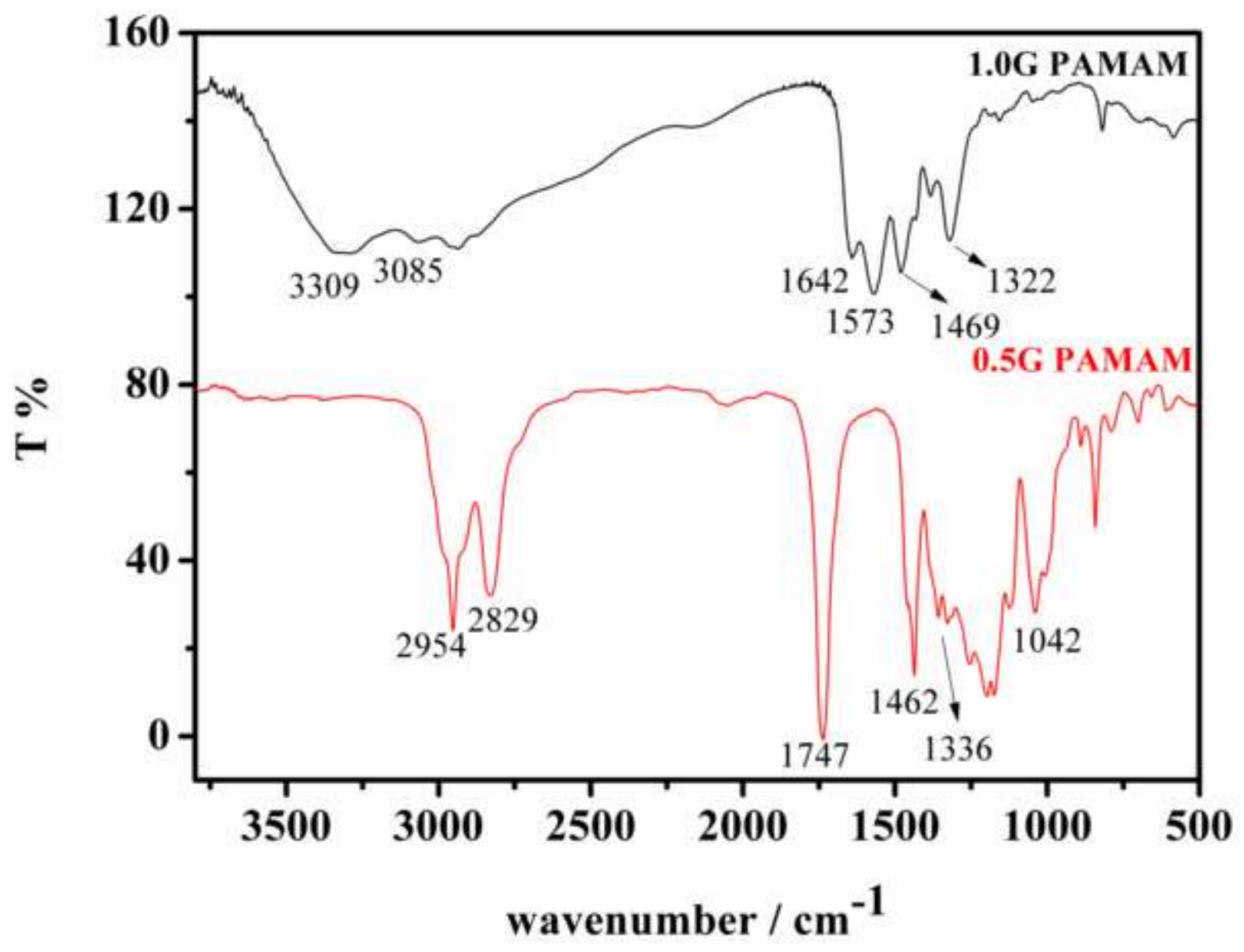



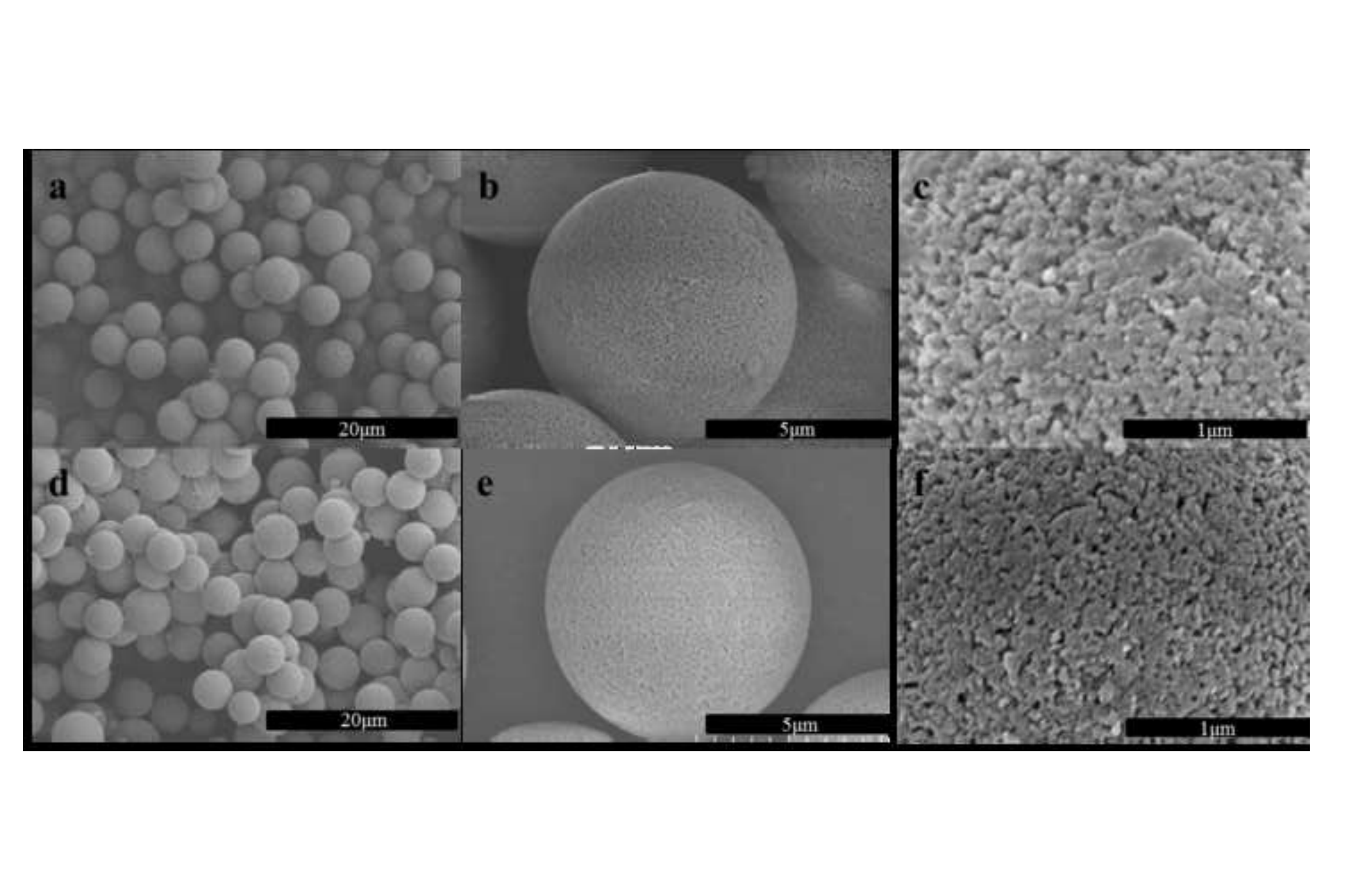

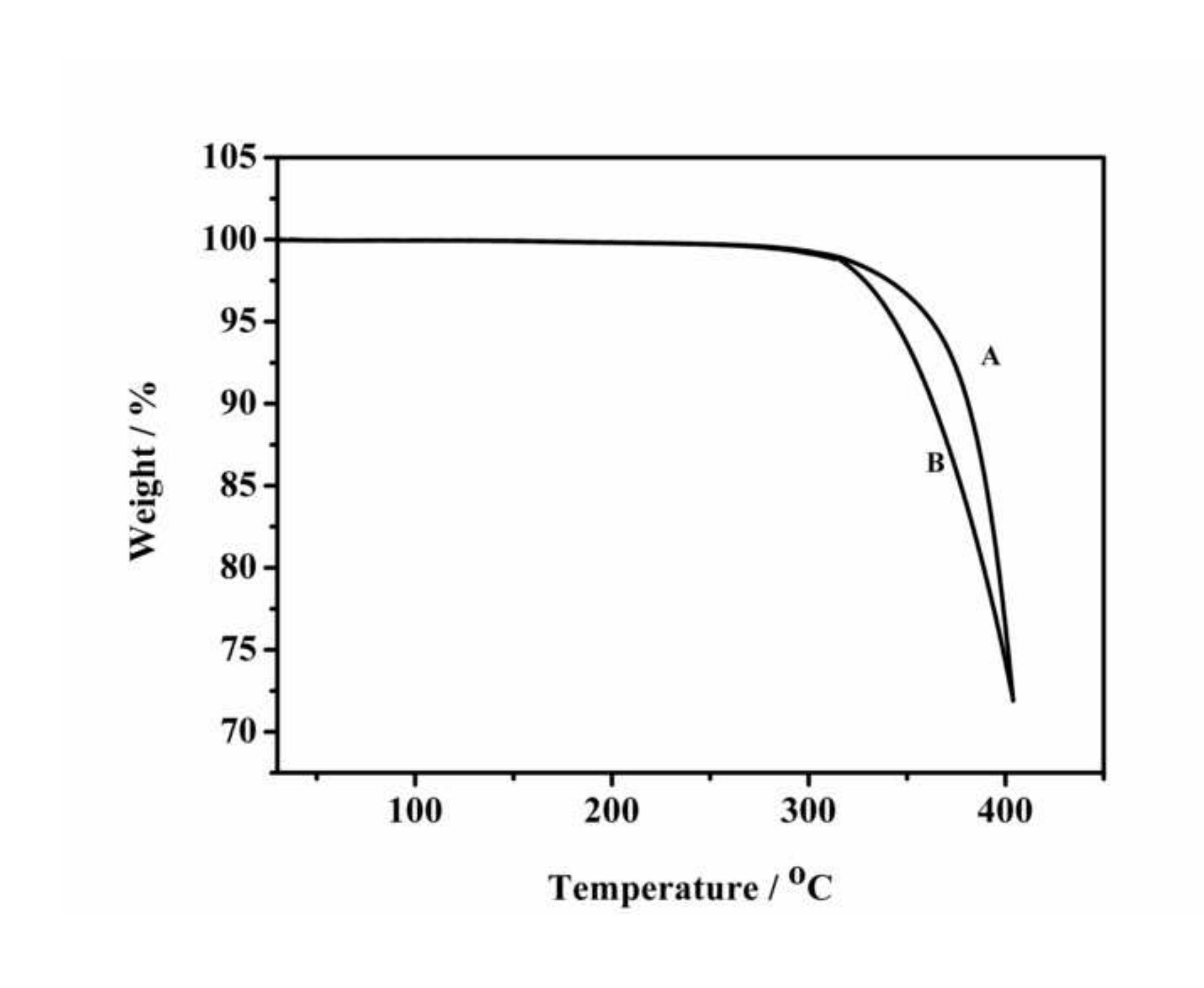

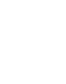

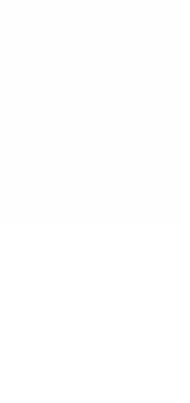
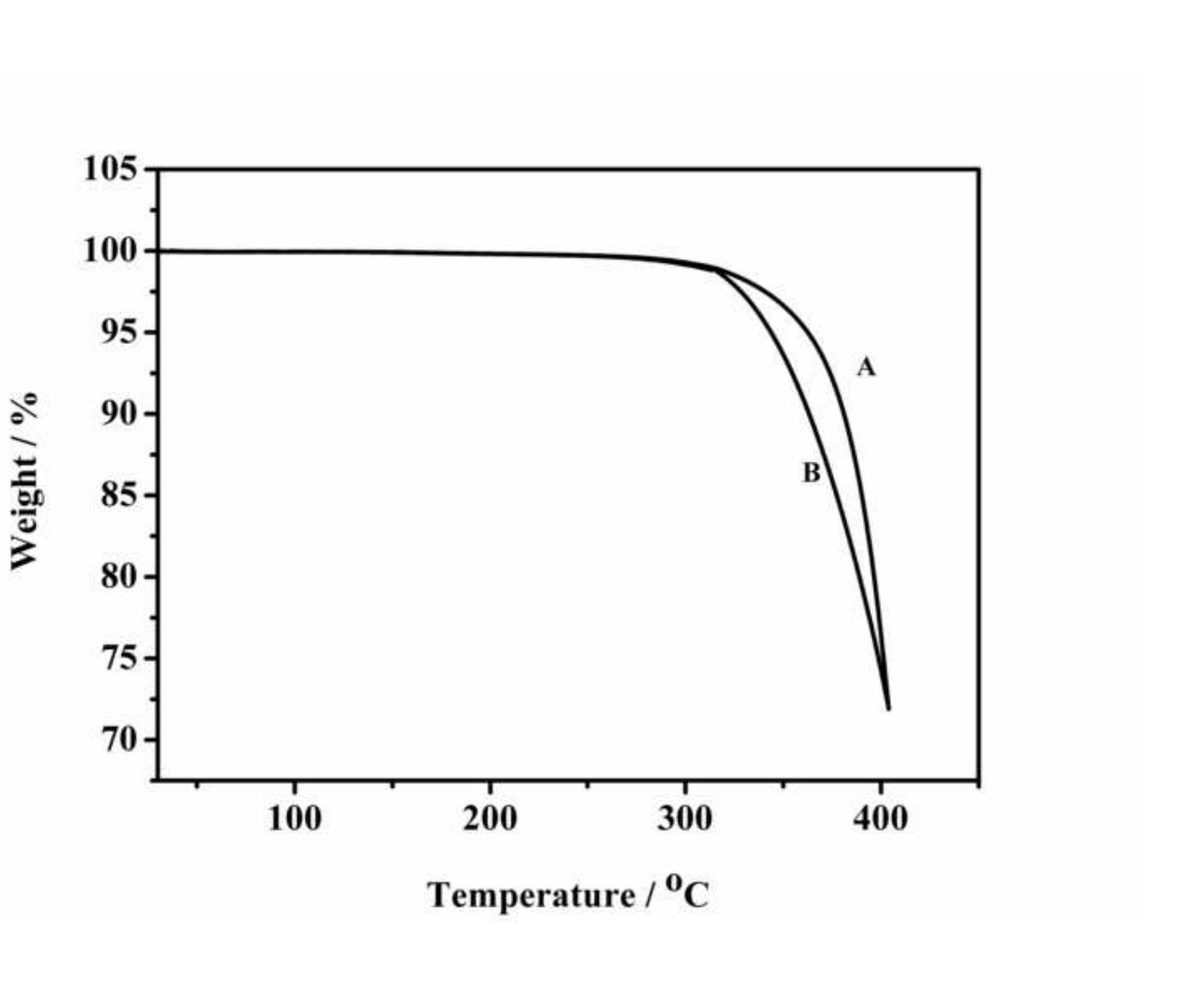


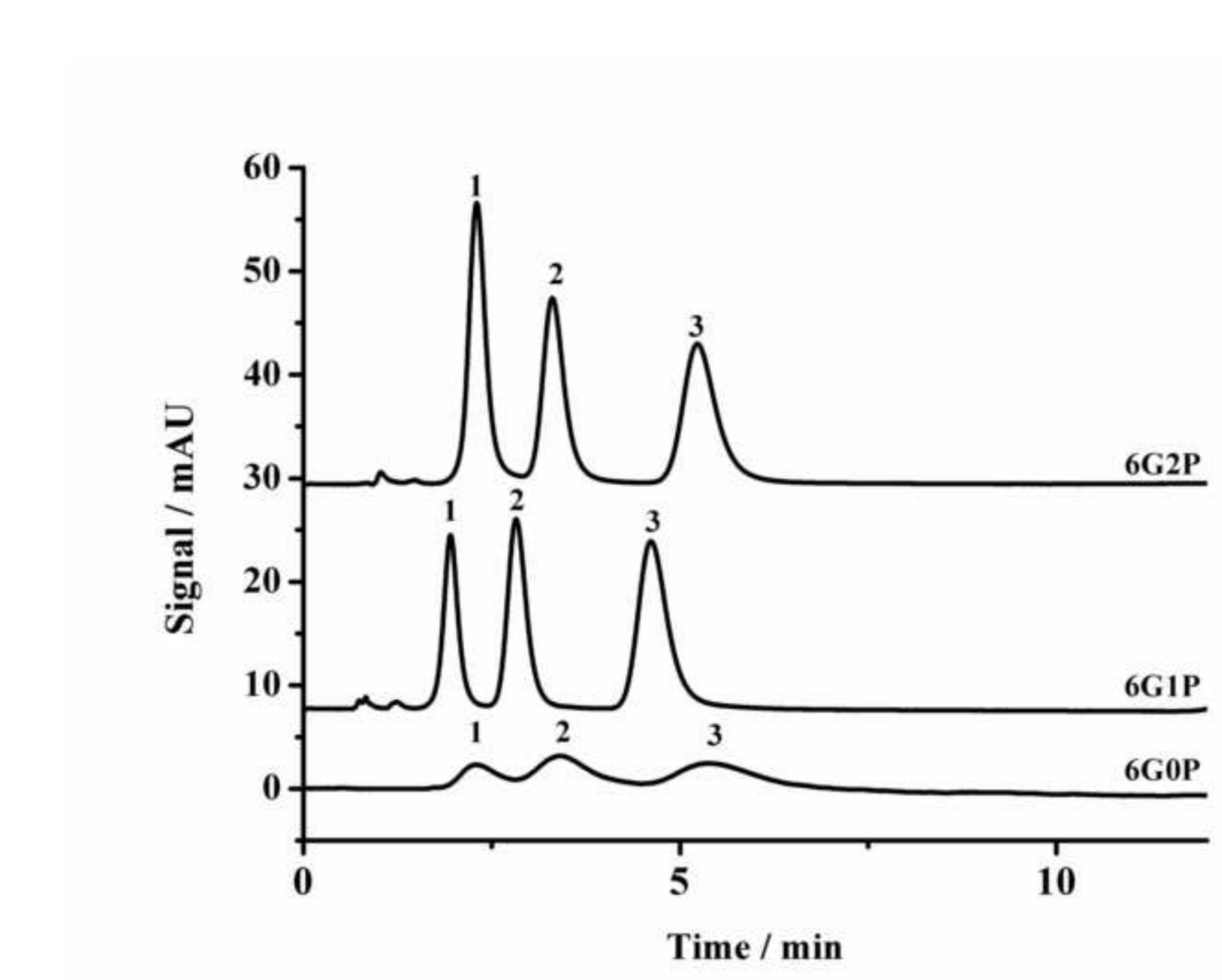

Time / min

Time / min 


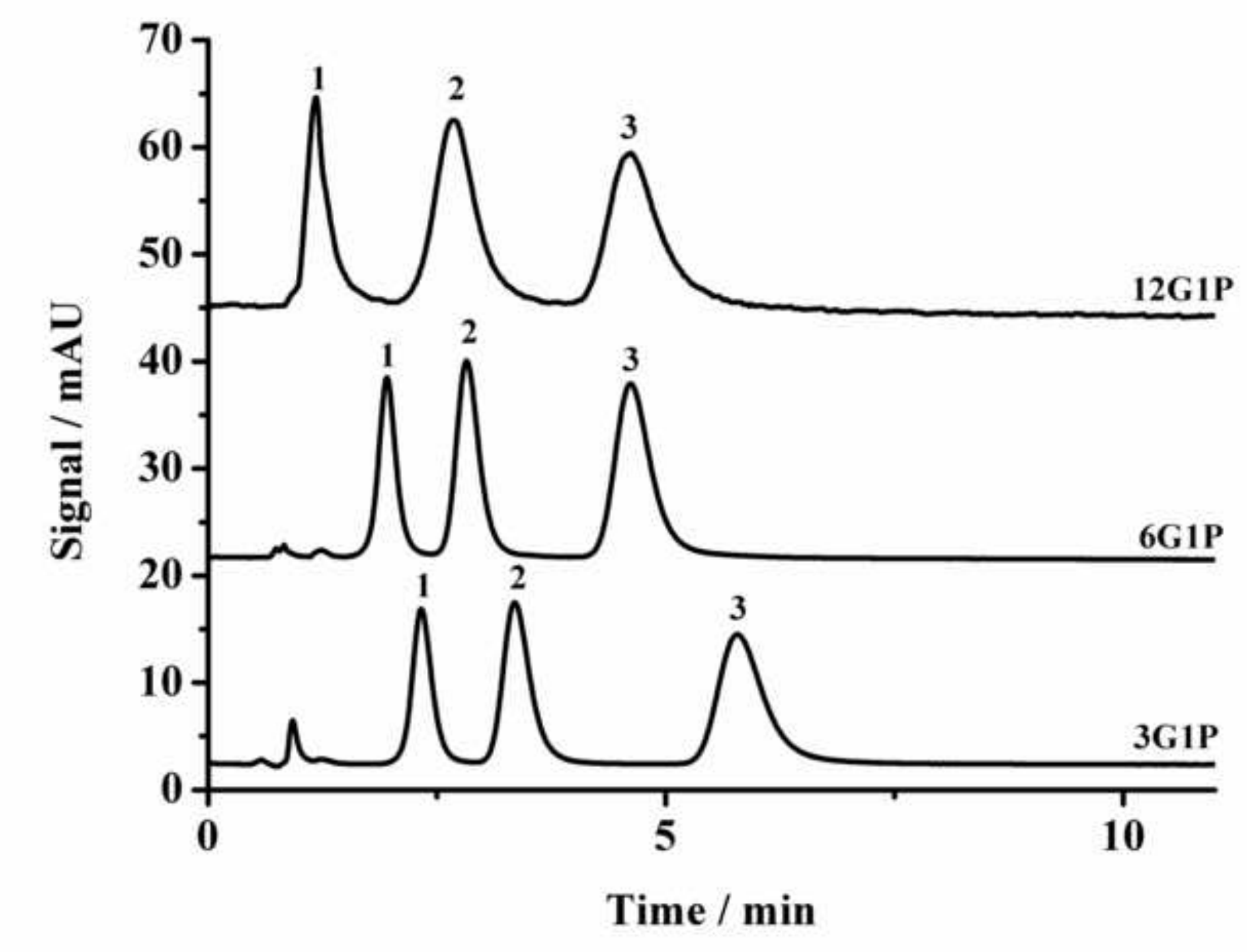

Time / min 


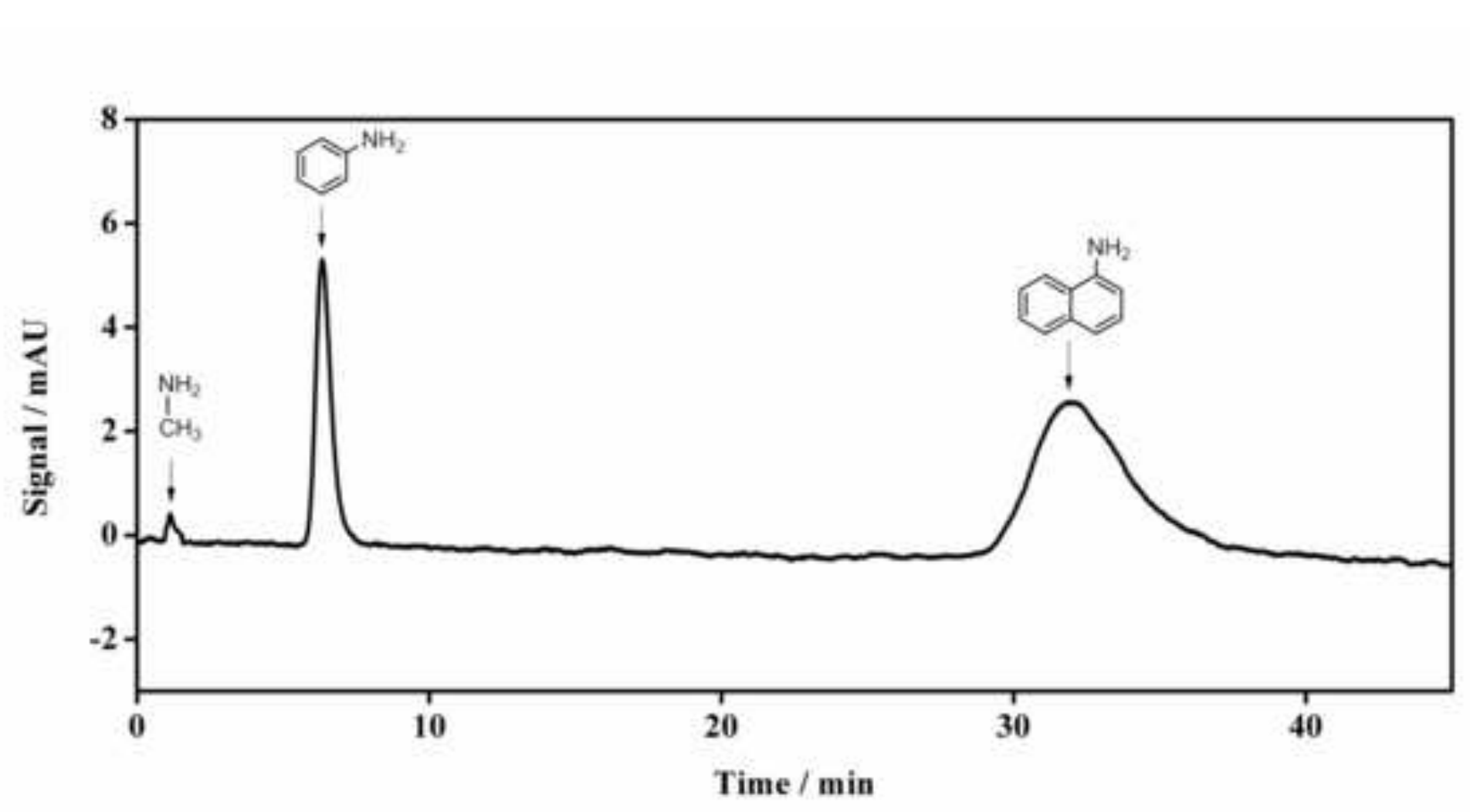

Fig 9;

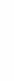

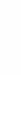

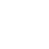

\author{
Time/ min
}

(T)
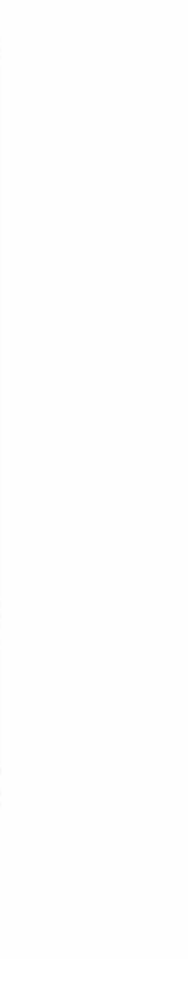


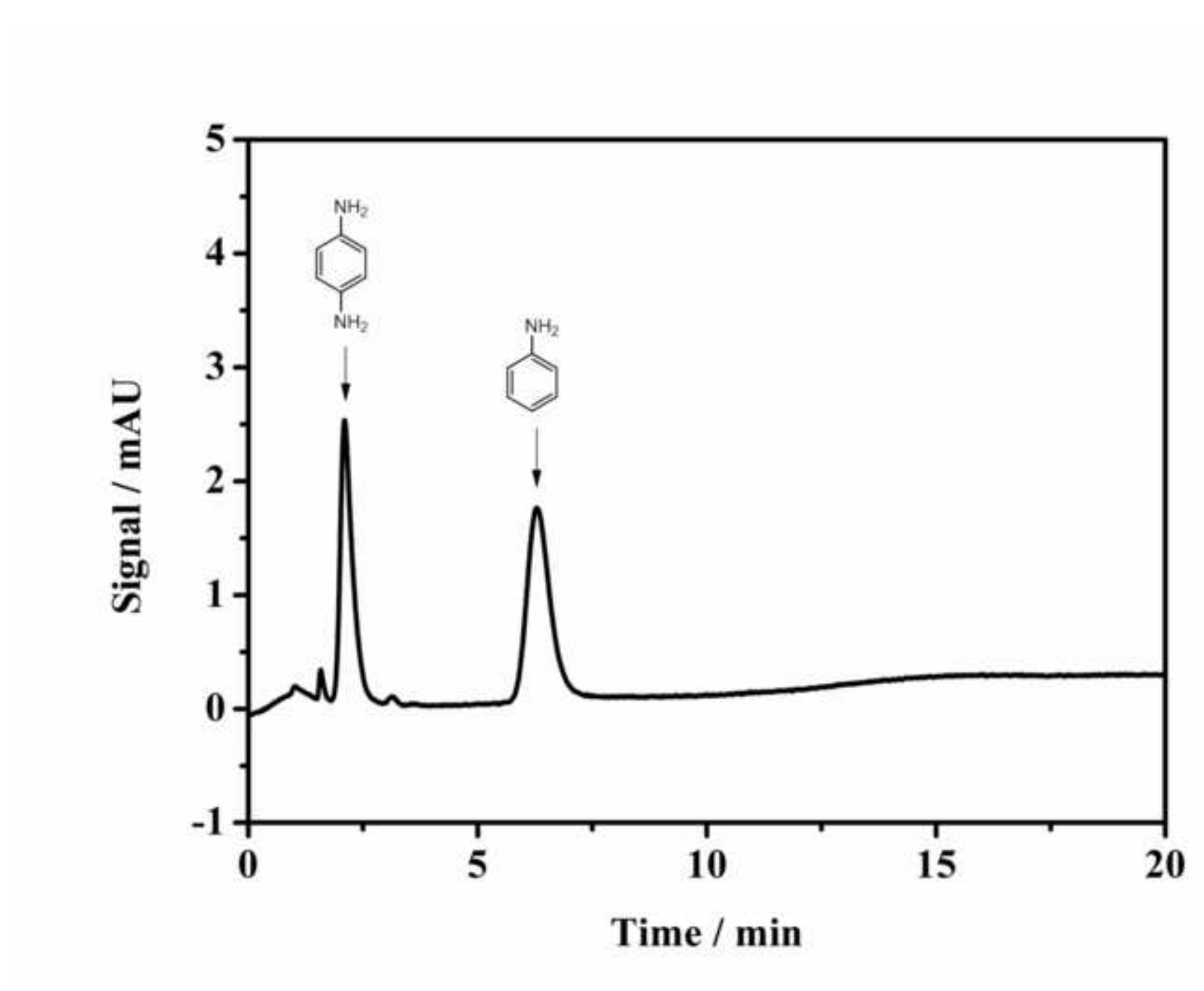

Time / min

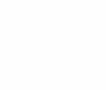

.

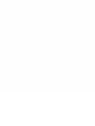

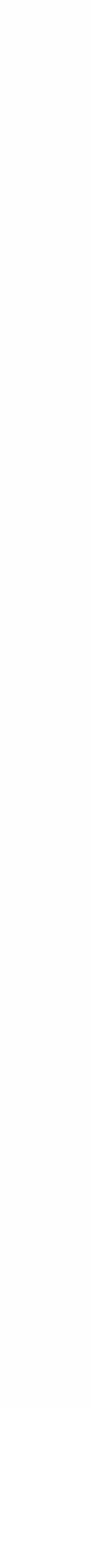



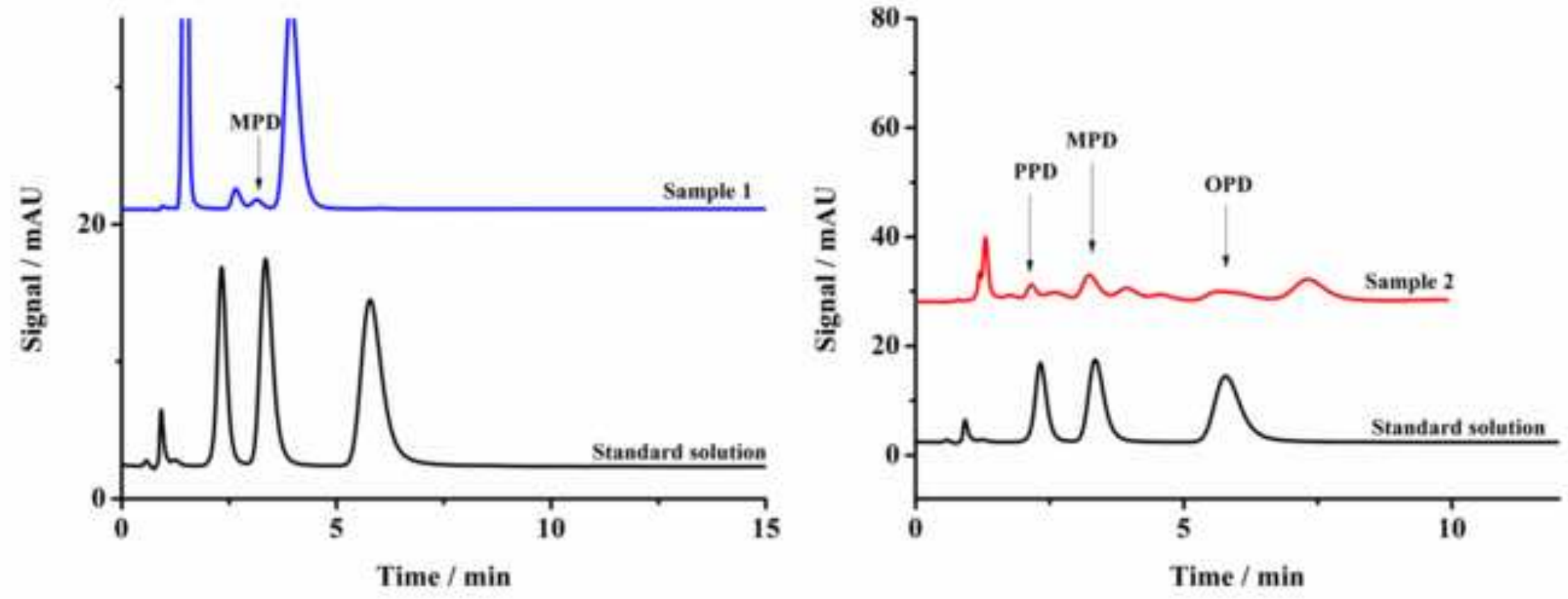